\title{
Effect of slope angle variation on the structures resting on hilly region considering soil-structure interaction
}

\author{
Rahul Ghosh $^{1} \cdot$ Rama Debbarma ${ }^{1}$
}

Received: 6 June 2018 / Accepted: 1 February 2019 / Published online: 12 February 2019

(c) The Author(s) 2019

\begin{abstract}
Structures resting on sloping ground are highly vulnerable to earthquakes due to irregularities in plan and elevation. Structures are often analysed under earthquake loadings, without considering the effect of soil-structure interaction (SSI). This practice is not advisable from practical point of view. In this present study, an attempt has been made to study the effect of slope angle variation for the structures resting on sloping ground, considering the base of the structures fixed as well as flexible (SSI). The analysis is performed in equivalent static force method (ESFM), response spectrum method (RSM), time history method (THM), nonlinear static method (NLSM) and nonlinear time history method (NLTHM). Results expose the criticality associated with increment of slope angle, with and without SSI consideration. Importance of considering SSI in seismic analysis is also revealed.
\end{abstract}

Keywords Structures $\cdot$ Sloping ground $\cdot$ Irregularity $\cdot$ soil-structure interaction $\cdot$ Nonlinear time history method

\section{Introduction}

Strong earthquakes strike frequently at different parts of the world causing destruction to life and all kind of structures. All kind of structure is vulnerable to earthquake loading, but the structures with irregularities are proved to be the most vulnerable. The insufficiency of plain ground in hilly region compels for construction activity on hilly slopes. Formation of plain area by earth excavation for construction is very costly and time consuming; on the other hand, it destroys the natural beauty of the landscapes. Financial development and quick urbanisation in these sloping areas have been quickened because of the land improvement. As a result, population density has increased enormously and unbalanced ratio of land availability to land requirement is observed in the hilly regions. Therefore, the construction of multi-storeyed building on hill slopes has gained popularity. While designing, it must be noticed that structures on inclines are not the same as those in plain land, i.e. they are

Rama Debbarma

ramadebbarma@gmail.com

Rahul Ghosh

rahulrazghosh@gmail.com

1 Department of Civil Engineering, National Institute of Technology Agartala, Agartala, Tripura 799046, India exceptionally unpredictable and unsymmetrical in flat and vertical planes. Such buildings have mass and stiffness varying along the vertical and horizontal planes; as a result, the centre of mass and centre of rigidity do not coincide on various floors and twisting of structures takes place. Considering the scenario, it is very important to investigate the responses of such buildings to make them earthquake resistant and prevent their collapse to save the loss of life and property. Hilly slopes are inconsistent, so the effect of slope variation on the structures must be studied under earthquake load. Most of the time, bases of the structures are considered as fixed, i.e. bases are assumed to be infinitely rigid. This concept is not true as the soil under the structure is flexible; so, SSI must be considered to get the realistic response of the structure. Prashant and Kori (2013) performed a study on the building situated on hill slope ( $27^{\circ}$ with horizontal) to bring out the effect of soft storey on the response of structure. Birajdar and Nalawade (2004) contemplated the seismic reaction of three diverse arrangement of structures arranged on slopping ground and found that stepback-setback structures were more appropriate on inclining ground. Halkude et al. (2013) performed reaction range investigation on two sort of building outlines specifically stepback frames and stepback-setback building outlines on inclining ground. Stepback and setback building frames observed to be more reasonable on slanting ground, contrasted with stepback frames. Kalsulkar 
and Rathod (2015) examined the stepback frames and stepback-setback frames on the inclining ground by RSM, with differing number of bays. Stepback-setback frames were less vulnerable than stepback frames and more noteworthy number of bays was better under seismic conditions. Arjun and Arathi (2016) contemplated the conduct of four-storied, sloped frame building having stepback-setback design for sinusoidal ground movement with various slope angles by performing RSM. Short column was damaged more during the quake. Thombre and Makarande (2016) made comparison between sloping ground, with different slope and plain ground buildings in response spectrum method. The displacement of building showed the same behaviour as of regular building but displacement's value reduced with the increment of slopes, due to curtailment of column on sloping ground. Nagarjuna and Patil (2015) observed that short columns were affected more during the earthquake, and for construction of the building on sloping ground, the stepback-setback building configuration was suitable, along with shear walls at the corner of the building. Kumar et al. (2014) performed seismic analysis of a five-storey RCC building on varying slope angles and compared with the same on the flat ground using linear static method. The footing columns of shorter height attracted more forces, because of a considerable increase in their stiffness, which in turn increased the shear and bending moment significantly. Khadiranaikar and Masali (2014) reviewed number of studies and found that most of the studies agree that the buildings resting on sloping ground has higher displacement and base shear compared to buildings resting on plain ground, and the shorter column attracts more forces and undergo damage when subjected to earthquake. Stepback building proved more vulnerable to seismic excitation. Ghosh and Debbarma (2017) investigated the performance of setback buildings with open ground storey on plane and sloping ground and proposed techniques to overcome the risk of their failure.

\section{Details of building and modelling of structure}

Five-storey $(G+4)$ residential building of 15 -m height and $15 \mathrm{~m} \times 15 \mathrm{~m}$ square plan, with 5 Nos. of bay (each bay @ $3 \mathrm{~m}$ ) is considered for analysis. The 3D view and plan of the building are shown in the Figs. 1 and 2.

Seismic design data are as follows:

Seismic zone: $V$, zone factor $(Z)$ : 0.36 , soil type: medium soil. Damping ratio: 5\%, frame type: special moment resisting frame, response reduction factor $(R)$ : 5 , Importance factor (I): 1 .

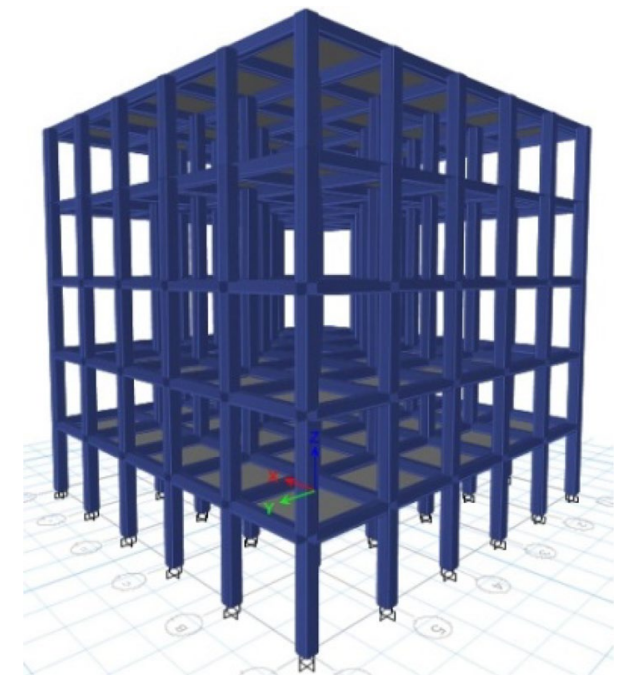

Fig. 1 3D view of the building

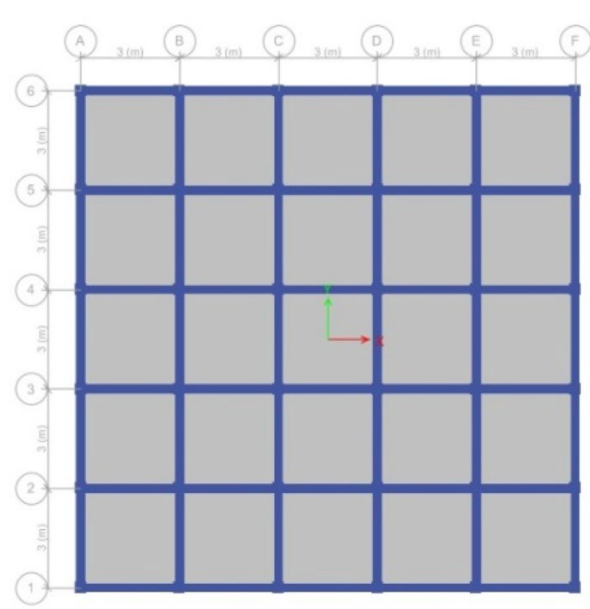

Fig. 2 Plan of the building

Material properties are taken as, unit weight of concrete: $25 \mathrm{kN} / \mathrm{m}^{3}$, characteristic strength of concrete: $30 \mathrm{MPa}$, characteristic strength of steel: $415 \mathrm{MPa}$.

Structural elements are, beam: $250 \mathrm{~mm} \times 300 \mathrm{~mm}$, column: $350 \mathrm{~mm} \times 350 \mathrm{~mm}$, slab thickness: $150 \mathrm{~mm}$, parapet height: $1000 \mathrm{~mm}$.

The types of load considered during the analysis are dead loads (DL) of beams, columns, slab, wall load (WL), live load (LL) of $3 \mathrm{kN} / \mathrm{m}^{2}$ at floors and $1.5 \mathrm{kN} / \mathrm{m}^{2}$ at roof, mass source $(1 \mathrm{DL}+1 \mathrm{WL}+0.25 \mathrm{LL})$.

\section{Description of models}

Total 8 Nos. of bare frame models are studied. Models are considered on the $0^{\circ}, 15^{\circ}, 30^{\circ}$ and $45^{\circ}$ slopes, respectively, with and without SSI considerations. Descriptions and names of the models are given in Table 1. The central panels (Panel C) of models are shown in Fig. 3. 


\section{Details of SSI spring modelling}

The effect of SSI at the base of the structure is simulated by assigning total 6 nos. of springs at the footings of each column for $6 d f$. Spring stiffness for each individual column is calculated using formulas proposed by Gazetas 1991, as given below (Eqs. 1, 2, 3, 4, 5, 6).

Table 1 Description of different models

\begin{tabular}{lll}
\hline $\begin{array}{l}\text { SL no. } \\
\text { the models }\end{array}$ & $\begin{array}{l}\text { Name of } \\
\text { Mescription of the model }\end{array}$ \\
\hline 1 & MF0 & Bare frame model with fixed base in $0^{\circ}$ slope \\
2 & MF15 & Bare frame model with fixed base in $15^{\circ}$ slope \\
3 & MF30 & Bare frame model with fixed base in $30^{\circ}$ slope \\
4 & MF45 & Bare frame model with fixed base in $45^{\circ}$ slope \\
5 & MS0 & Bare frame model with SSI at base in $0^{\circ}$ slope \\
6 & MS15 & Bare frame model with SSI at base in $15^{\circ}$ slope \\
7 & MS30 & Bare frame model with SSI at base in $30^{\circ}$ slope \\
8 & MS45 & Bare frame model with SSI at base in $45^{\circ}$ slope \\
\hline
\end{tabular}

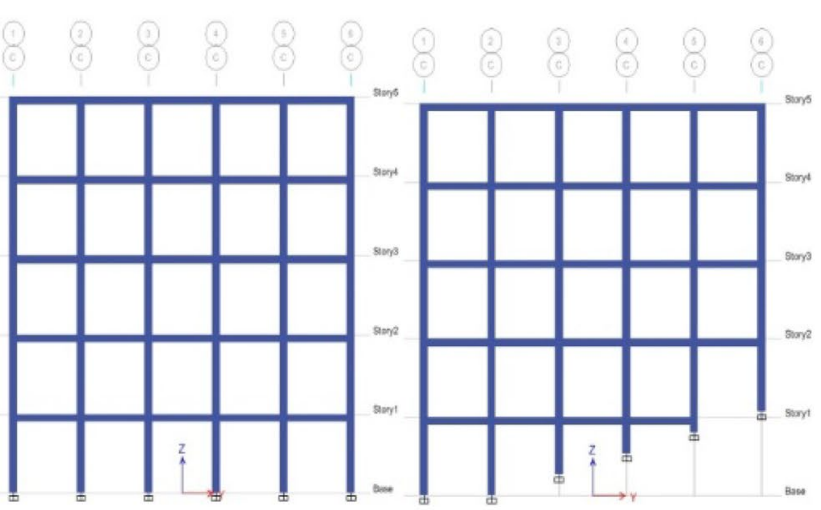

MF0

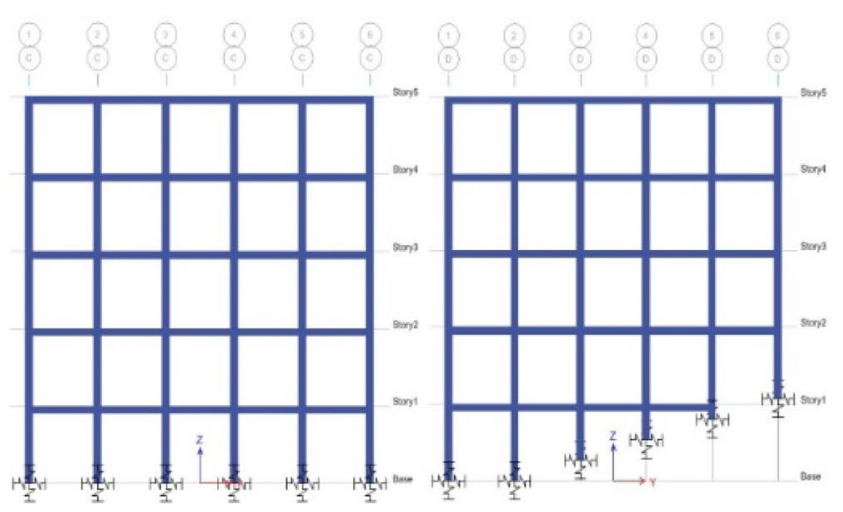

MS0
MF15

MS15

$K_{Z}=\frac{2 G L}{(1-\vartheta)}\left[0.73+1.54 X^{0.75}\right]$

$K_{y}=\frac{2 G L}{(2-\vartheta)}\left[2+2.5 X^{0.85}\right]$

$K_{x}=K_{y}-\frac{0.2 G L}{(0.75-\vartheta)}\left[1-\frac{B}{L}\right]$,

$K_{r x}=\frac{G}{(1-\vartheta)} I_{b x}^{0.75}\left(\frac{L}{B}\right)^{0.25}\left[2.4+0.5\left(\frac{B}{L}\right)\right]$,

$K_{\text {ry }}=\frac{3 G}{(1-\vartheta)} I_{\text {by }}^{0.75}\left(\frac{L}{B}\right)^{0.75}$,

$K_{t}=3.5 G I_{b z}^{0.75}\left(\frac{B}{L}\right)^{0.4}\left(\frac{I_{b z}}{B^{4}}\right)^{0.2}$

where

$X=\frac{A_{b}}{4 L^{2}}$

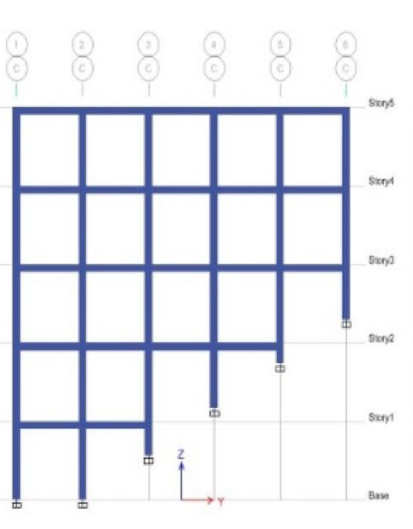

MF30

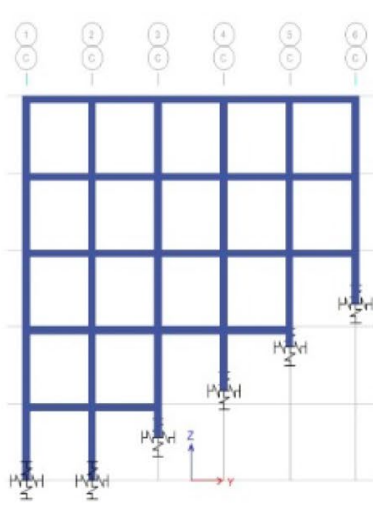

MS30

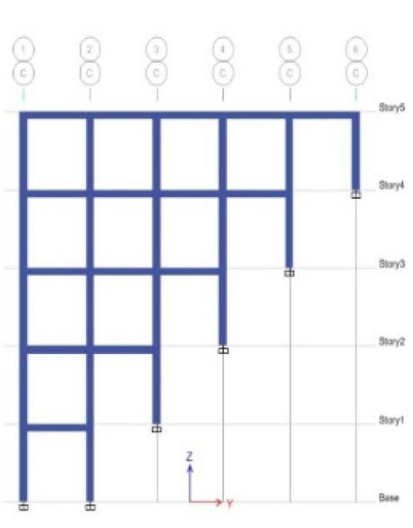

MF45

Fig. 3 2D view of the central panels of different models 
$A_{b}=$ area of foundation, $I_{b x}=$ moment of inertia about longitudinal axis, $I_{b y}=$ moment of inertia about lateral axis, $I_{b z}=$ moment of inertia about vertical axis, $B=$ half of the width of foundation, $L=$ half of the length of foundation, $K_{Z}=$ translational stiffness in vertical direction, $K_{y}=$ translational stiffness in lateral direction, $K_{x}=$ translational stiffness in longitudinal direction, $K_{r x}=$ rotational stiffness about longitudinal axis, $K_{r y}=$ rotational stiffness about lateral axis, $K_{t}=$ rotational stiffness about vertical axis

The soil properties are taken as per Chougule and Dayavanal (2015).

Bearing capacity of soil $(q)=160 \mathrm{kN} / \mathrm{m}^{2}$

Density of soil $(\gamma)=18 \mathrm{kN} / \mathrm{m}^{3}$

Angle of repose $(\varnothing)=29^{\circ}$

Poisson's ratio $(\vartheta)=0.45$

Elastic modulus of soil $(E)=50,000 \mathrm{kN} / \mathrm{m}^{2}$

Shear modulus of soil $(G)=17,241.38 \mathrm{kN} / \mathrm{m}^{2}$

\section{Methods of analysis}

In this study, all the models are analysed in linear static method which is known as ESFM, linear dynamic method, which is known as RSM, linear time history analysis method and NLSAM, which is known as pushover analysis. Linear analysis is performed using the software ETABS 2015 and for nonlinear analysis SAP2000 is used. Default nonlinear hinges are assigned in columns and beams as per American Society of Civil Engineers, ASCE/SEI 41-13 (2014) or Federal Emergency Management Agency, FEMA-356 (2000) for pushover analysis. ESFM analysis and RSM analysis are carried out and results are compared to study the seismic behaviour of the structures. In modal analyses, mode shapes are generally obtained in normalised form, for that the results of response spectrum method need to be properly scaled. In the present study, the scaling has been done by equating the base shears obtained from ESFM and RSM as per IS 1893 (2002). In ESFM analysis, different combinations like dead load (DL) and earthquake load (EL) as suggested in IS 1893 (2002) are created and the combination $1.5(\mathrm{DL} \pm \mathrm{EL})$ has given the maximum effect. Real earthquake data of Kobe earthquake are used for time history analysis.

\section{Results and discussion}

The results of ESFM and RSM analysis for different models, considering different parameters are initially compared and effect of slope angle variation along with SSI consideration is explored. Time history analysis results and results of pushover analysis are presented thereafter.

\section{Time period}

Fundamental time period of the models are presented in Fig. 4. Percentage variations of time periods due to implementation of SSI are given in Table 2, according to different slope angles.

It is noticed that with the increment of the slope, the fundamental time period of the models gets reduced. The reduction of column length increases the structural stiffness; as a result, the time period reduces. Models on $45^{\circ}$ slope (MF45 and MS45) show marginal increase of time period compared to the models on $30^{\circ}$ slope (MF30 and MS30). The models on $15^{\circ}$ slope (MF15 and MS15) and $30^{\circ}$ (MF30 and MS30) slope have intermediate column length (in between 0 and $3 \mathrm{~m}$ ) in different storey levels along the height, which does not allow the storeys to vibrate freely as a complete storey. These intermediate columns provide additional stiffness to those storeys and reduce the time period of the models, but the models on $45^{\circ}$ slope (MF45 and MS45) get a complete storey on each level, which results in a minor increase in flexibility as well as in time period.

All the models, where SSI has been considered, exhibit a larger time period compared to the fixed base models, due to increased flexibility of the base of the structures. Interestingly, the percentage increment of time period due to SSI implementation has also increased with the increase in slope angle.

\section{Base shear}

Base shear is a function of spectral acceleration, which depends on mass and stiffness of the structure, and these are presented in Fig. 5.

Base shear is increased with the increment of the slope angle due to increased spectral acceleration and reduced time

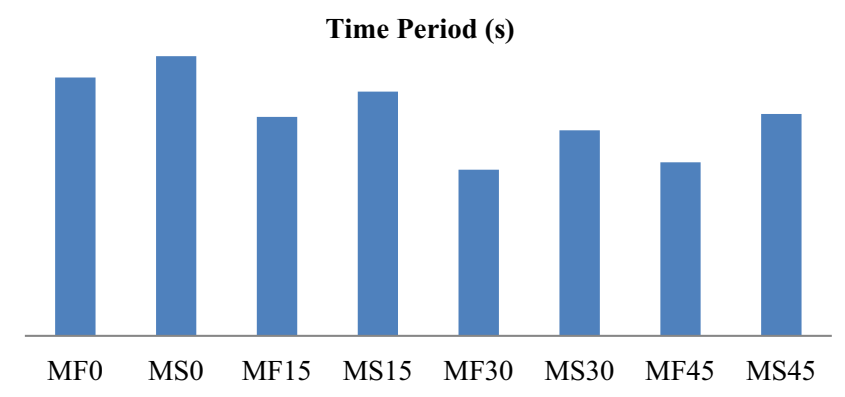

Fig. 4 Fundamental time periods of models 
Table 2 Percentage variation of time periods
Percentage reduction of time period with increase in slope angle $(\%)$
Percentage increment of time period due to SSI implementation (\%) along slope angle

$\begin{array}{llll}0^{\circ} & 15^{\circ} & 30^{\circ} & 45^{\circ} \\ 7.675 & 10.378 & 19.158 & 21.774\end{array}$

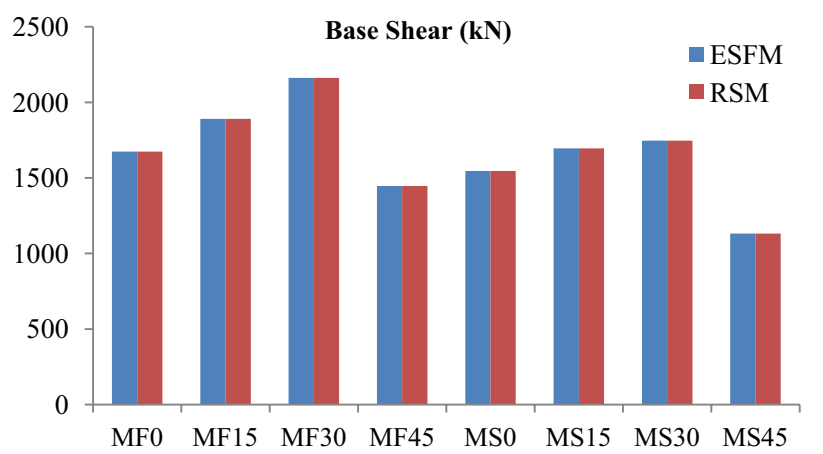

Fig. 5 Base shear of models

period, except models on the $45^{\circ}$ slope. The models on $45^{\circ}$ slope have marginal increase of flexibility and time period, but maximum decrease in the floor area and mass. The base shears of these models are dropped for this reason. Implementation of SSI at the base of the structure reduces the base shear due to increased flexibility of the structures. Percentage reduction of floor area with increase in slope angle and base shear reduction due to SSI consideration is given in Table 3 .

It is noticed that percentage reduction of base shear due to SSI consideration is increased with the increase of slope.

\section{Displacement}

Displacement profiles in major direction ( $X$ direction) and minor ( $Y$ direction) direction of force, with the storey height for different models in ESFM and RSM are shown in Fig. 6.

Displacements in the direction of force ( $X$ direction), increased along the storey height and reduced with the increment of the slope. Bidirectional displacement ( $X$ and $Y$ direction) for unidirectional force (in $X$ direction) is noticed for the models resting on slope but here the displacement values got increased with the increment of slope. The displacement of the taller side of the models has been found larger in comparison of the shorter side of the model, which means taller side on the lower level of slope is more flexible than the shorter side at the higher level of the slope. The models with SSI show comparatively larger values of displacement from the model with fixed base in both directions.

\section{Column bending moment}

A central panel ( $\mathrm{C}$ panel) is selected for presenting variation of column bending moments of every model, which is shown in Fig. 7.

It is observed that in both methods, the amount of bending moment, in every column of each individual storey is almost similar for the models of $0^{\circ}$ slope (MF0 and MS0). Maximum bending moment is at ground storey (GS) columns and the value of bending moments reduces with the increment of storey height in models of $0^{\circ}$ slope. But in the models other than $0^{\circ}$ slope, the columns of the shorter side of the structure at the higher level of the slope is facing higher bending moment compared to the columns of taller side at lower level of the slope. So in models resting on sloping ground, within a particular storey there is huge variation of column forces and the columns with higher bending moment at the upper side of the slope are affected severely during earthquake. Increment of the column bending moment in the upper side of the slope is noticed with increase of slope angle. Slope angle variation results in the formation of intermediate column lengths (in between 0 and $3 \mathrm{~m}$ ) at different storey level of models resting on $15^{\circ}$ and $30^{\circ}$ slopes. These reduced columns carry higher bending moments compared to full-length columns.

Interestingly, despite having full length of column in upper storey level at higher side of slope, the column bending moments increased just due to increment of slope angle. Bending moment variation of column C6 of 5th storey (C6S5) and column C5 of 4th storey (C5S4) is presented in Table 4.

The columns C6S5 and C5S4, which are taken for example, have full column length in every model. Bending moments in these columns have increased not because of
Table 3 Reduction of floor area due to slope increment and base shear reduction for SSI consideration

\begin{tabular}{|c|c|c|c|c|c|c|c|}
\hline \multicolumn{4}{|c|}{$\begin{array}{l}\text { Percentage reduction of floor area in different slope } \\
\text { angle }(\%)\end{array}$} & \multicolumn{4}{|c|}{$\begin{array}{l}\text { Percentage reduction of base shear due to SSI } \\
\text { implementation (\%) along slope angle }\end{array}$} \\
\hline $0^{\circ}$ & $15^{\circ}$ & $30^{\circ}$ & $45^{\circ}$ & $0^{\circ}$ & $15^{\circ}$ & $30^{\circ}$ & $45^{\circ}$ \\
\hline 0 & 16.67 & 26.67 & 33.33 & 7.67 & 10.37 & 19.15 & 21.77 \\
\hline
\end{tabular}


Fig. 6 Displacement of models $\mathbf{a}$ at $X$ direction in ESFM, b at $X$ direction in RSM, $\mathbf{c}$ at $Y$ direction in ESFM and $\mathbf{d}$ at $Y$ direction in RSM

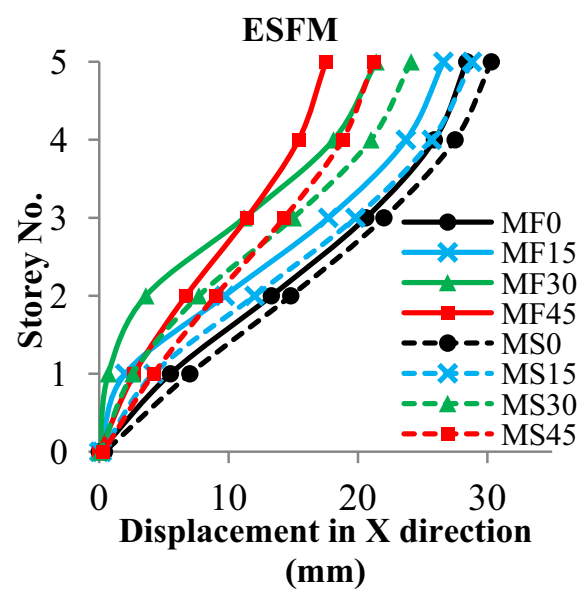

(a)

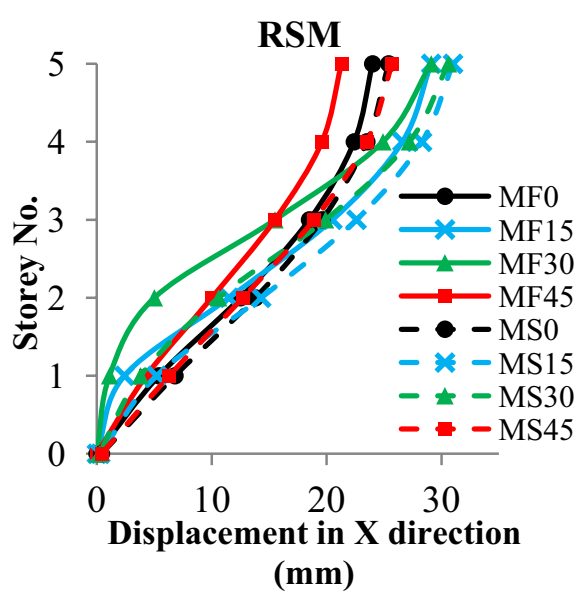

(b)

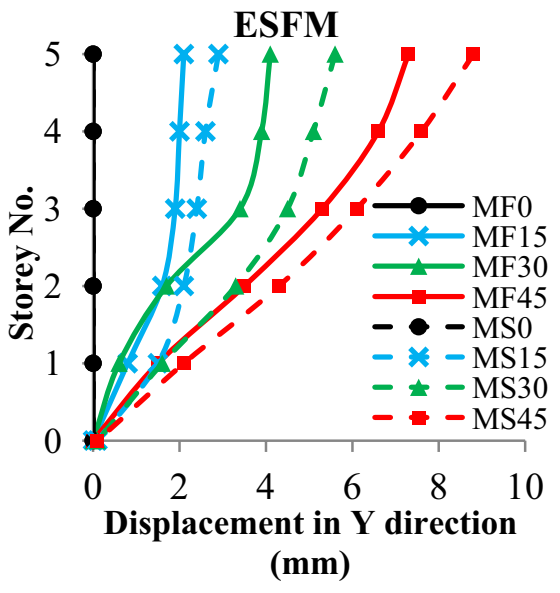

(c)

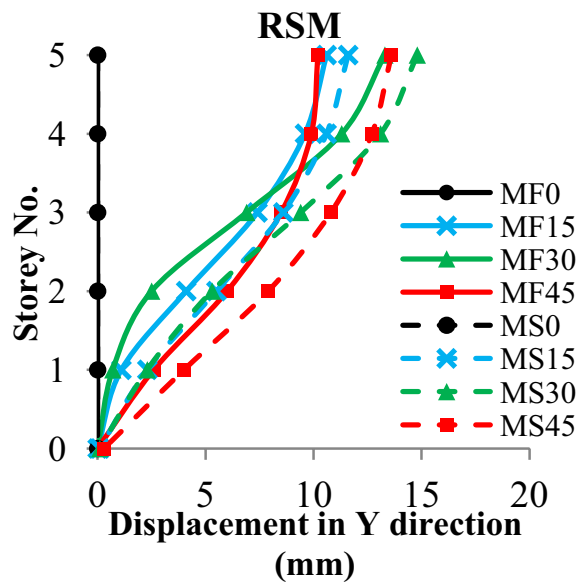

(d) length reduction, but because of increment of slope angle of the models. Even, the torsional moments in the columns of the structures resting on sloping ground have been amplified, with the increment of the slope angle, which is shown in Table 5.

Models with SSI consideration show almost same nature of bending moment variation along the slope, but value of bending moment compared to fixed base models is relatively lower. These results clearly indicate that whether there is reduction of column length or not, but there is definite increment of column bending moment with the increment of slope angle.

\section{Torsion}

Torsional effect arises from the eccentricity in a building, when the centre of mass of the building does not coincide with its centre of rigidity. If there is torsion, the building rotates about its centre of rigidity, due to torsional moment about the centre of structural resistance. As the structures are resting on sloping ground, these are irregular in vertical and horizontal planes, in terms of mass, stiffness, and layout. As a result of this, the torsional response is recorded and storey rotation about vertical $(Z)$ axis is shown in Fig. 8. It is noticed that torsional response increases with the increment of slope and storey height, but for models resting on $0^{\circ}$ slope (MF0 and MS0), rotational response is absent. The models with SSI at base have higher torsional effect compare to the fixed base models.

\section{Results of linear time history analysis}

Time history analysis is performed using the real ground motion data of Kobe earthquake, as shown in Fig. 9. Results are given in the Figs. 10, 11, 12.

Results show that maximum displacement in the direction of force ( $X$ direction), is in the models of $0^{\circ}$ slope (MF0 and MS0) and displacement values decreases in other models with increment of slope. Displacement in the minor direction of force ( $Y$ direction) is highest in the models of $45^{\circ}$ slope and values decrease with reduction of slope angle. Same nature of variation is observed in the 
Fig. 7 Column bending moment of models $\mathbf{a}$ in ESFM, $\mathbf{b}$ in RSM
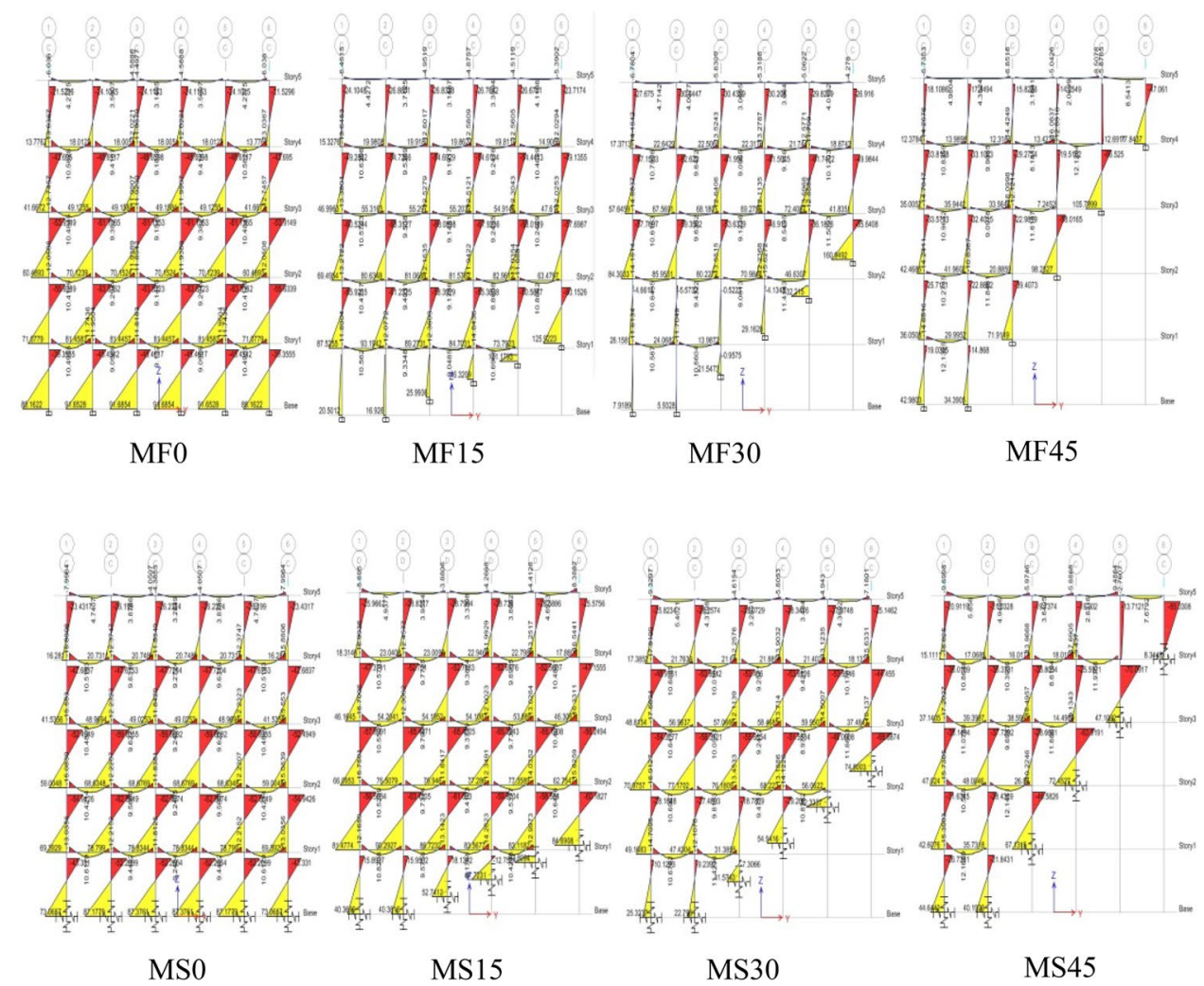

(a)
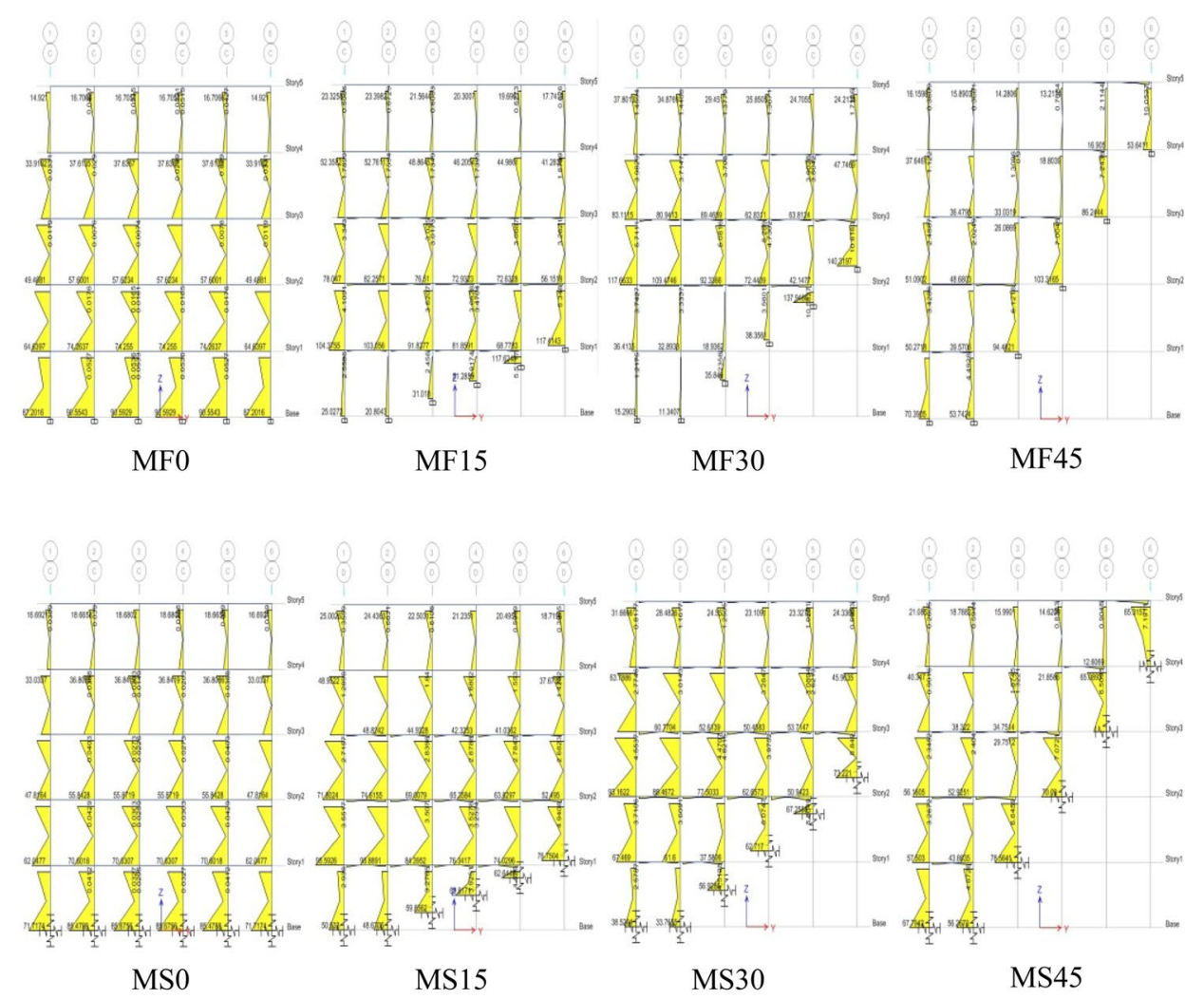

(b) 
Table 4 Change of bending moment of column due to variation of slope angle

\begin{tabular}{llllll}
\hline Models & \multicolumn{4}{l}{ Bending moment in columns $(\mathrm{kN}-\mathrm{m})$} \\
\cline { 2 - 3 } & \multicolumn{2}{l}{ C6S5 } & & C5S4 & \\
\cline { 2 - 3 } \cline { 5 - 6 } & ESFM & RSM & & ESFM & RSM \\
\hline MF45 & 77.843 & 53.641 & & 105.799 & 86.244 \\
MF30 & 18.874 & 24.213 & & 72.408 & 63.812 \\
MF15 & 14.908 & 17.740 & & 54.914 & 44.986 \\
MF0 & 13.776 & 14.920 & & 49.125 & 37.613 \\
\hline
\end{tabular}

Table 5 Change of column torsional moment due to variation of slope angle

\begin{tabular}{|c|c|c|c|c|}
\hline \multirow[t]{3}{*}{ Models } & \multicolumn{4}{|c|}{ Torsional moment in columns $(\mathrm{kN}-\mathrm{m})$} \\
\hline & \multicolumn{2}{|l|}{ C6S5 } & \multicolumn{2}{|l|}{ C5S4 } \\
\hline & ESFM & RSM & ESFM & RSM \\
\hline MF45 & 6.847 & 10.508 & 6.328 & 10.232 \\
\hline MF30 & 0.053 & 2.432 & 0.274 & 5.022 \\
\hline MF15 & 0.009 & 1.017 & 0.024 & 0.496 \\
\hline MF0 & 0.001 & 0.003 & 0.002 & 0.002 \\
\hline
\end{tabular}

case of torsional response and torsional response becomes nil in the models of $0^{\circ}$ slope. Models where the SSI is considered always show higher responses compared to the fixed base models due to increased flexibility.

\section{Results of pushover analysis}

The nonlinear static analysis is performed by displacement control technique in capacity spectrum method, as per guidelines of Applied Technology Council, ATC-40 (1996). In this method (Capacity Spectrum method, as

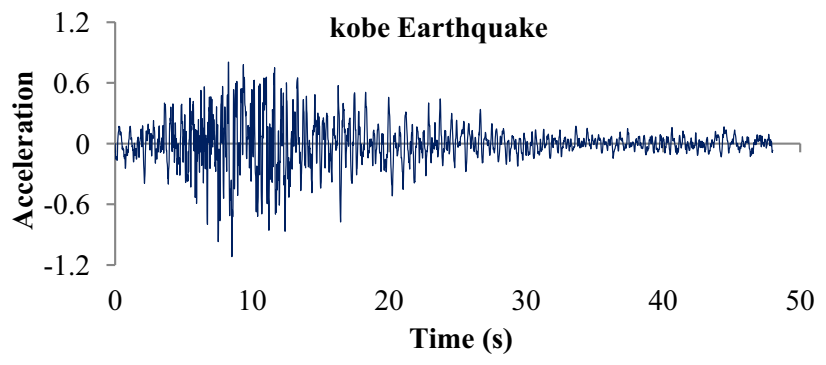

Fig. 9 Ground motion data of Kobe earthquake

per ATC-40), the capacity spectrum of the structure and demand curve, generates in a spectral displacement versus spectral acceleration domain. Capacity spectrum is nothing but the base shear versus roof displacement curve (capacity curve or pushover curve) plotted in a spectral displacement versus spectral acceleration domain. The intersection point of capacity curve of the structure and displacement demand curve is known as the performance point (PP). PP defines the overall performance of the structure under earthquake loading.

The pushover curves of all the models along with their PP are shown in Fig. 13, and displacement and base shear values at PP are given in Table 6.

Pushover curves reveal the vulnerability of all the models as the capacity curve of the models meets the displacement demand curve, far beyond the linear range (at PP) in the nonlinear stage with a large displacement value. Higher base shear carrying capacity is noticed with the increment of slope at $15^{\circ}$ and $30^{\circ}$ as the initial stiffness of the models increased. Models resting on $45^{\circ}$ (MF45 and MS45) show lesser base shear carrying capacity compared to models on $30^{\circ}$ slope and $15^{\circ}$ slope due to marginal increase of time period and maximum floor area reduction.
Fig. 8 Torsional response of models a in ESFM, b in RSM

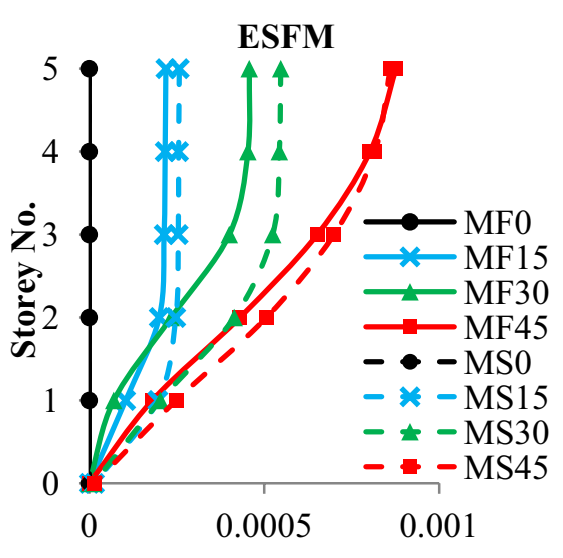

Rotation about $Z$ axis (rad)

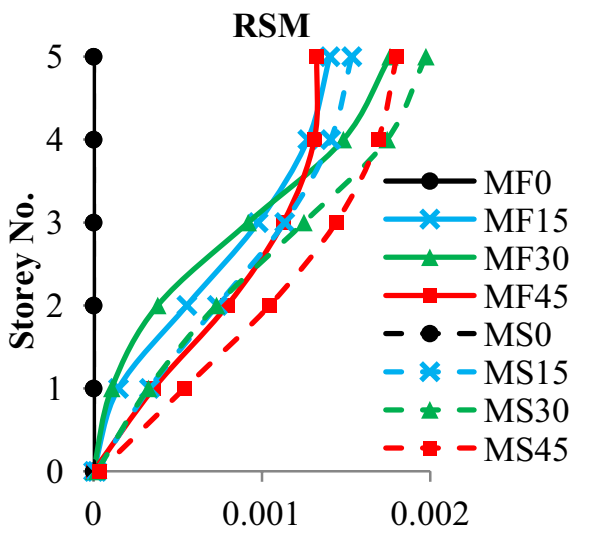

Rotation about $Z$ axis (rad)

(b) 


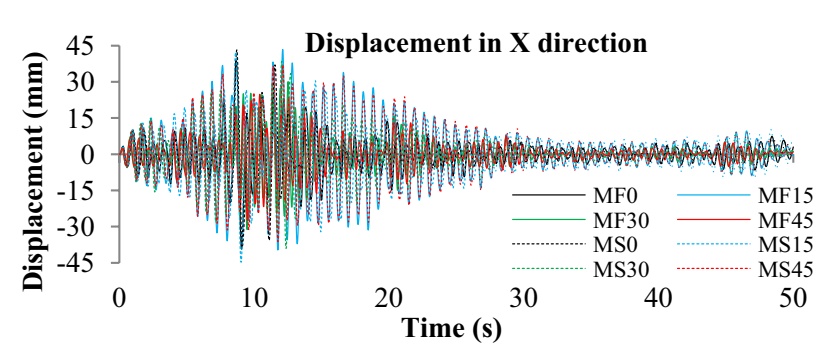

Fig. 10 Displacement in $X$ direction in time history analysis

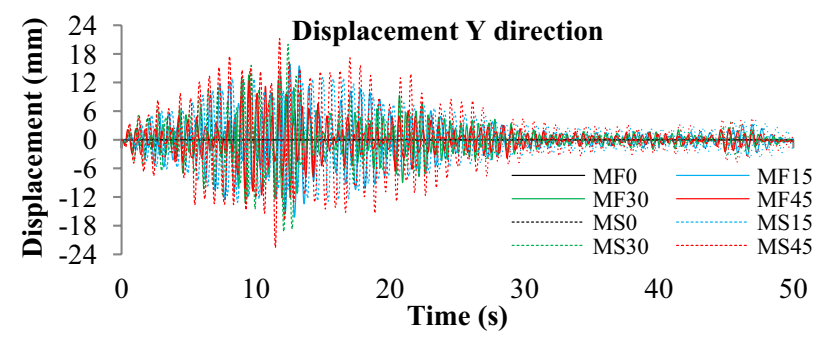

Fig. 11 Displacement in $Y$ direction in time history analysis

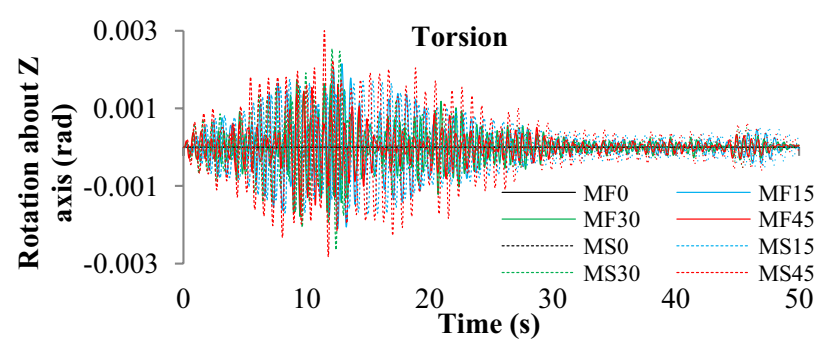

Fig. 12 Torsional response in time history analysis

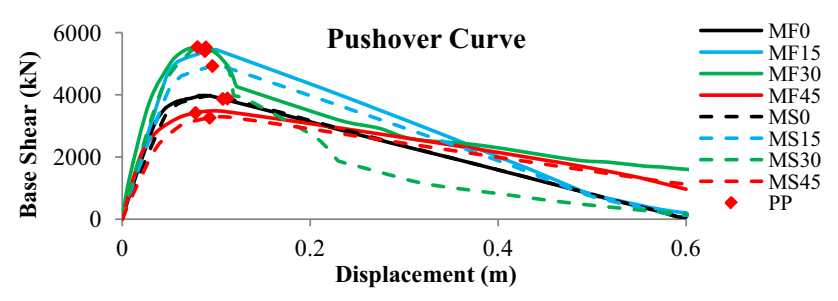

Fig. 13 Pushover curves including PP of different models

Models with SSI consideration give even more poor results compared to the fixed base models, because of higher displacement demand and lower base shear carrying capacity.

\section{Results of nonlinear time history analysis}

Nonlinear time history analysis, which explores more accurate responses of structure, is performed for all the models by direct integration technique, using the real ground motion data of Kobe earthquake. Results are presented in the Figs. 14, 15, 16.

Non-recoverable permanent deformation is noticed in most of the models by nonlinear time history analysis. After reaching the maximum responses corresponding to input acceleration, the models deform permanently and fail to regain their original phase. The variations of maximum responses for all models are extracted from nonlinear time history results and shown in Figs. 16, 17, 18, 19 and 20.

Extracted results from nonlinear time history imply that with the increment of slope angle, displacement in the direction of force ( $X$ direction) reduces for both fixed and flexible base. But displacement in the transverse direction of force ( $Y$ direction) goes on increasing with the increment of slope. Similar nature is noticeable in the case of maximum inter-storey drift at $X$ and $Y$ directions. Maximum torsional response also increases with the increment of slope angle. For each case, model with SSI exhibits more structural responses than the fixed base models (Fig. 21).

\section{Conclusions}

In this paper, the seismic analysis of the structures resting on different slope angle with and without SSI consideration is performed in static and dynamic methods as well as in linear and nonlinear methods. Structures on the sloping ground are found as more vulnerable than the structures on the plain ground, and the degree of vulnerability increases with the increment of slope angle. Under unidirectional force, orthogonal movement has been recorded for the structure on sloping ground. These structures on sloping ground also reflects differential movement of either sides of the structure, as the taller side moves more than the shorter side in the direction of force. This incident indicates the stiffness concentration on the shorter side of the structure on the higher level of the slopes. Due to the
Table 6 Base shear and displacement at performance point (PP) of the models

\begin{tabular}{lllllllll}
\hline Models & MF0 & MF15 & MF30 & MF45 & MS0 & MS15 & MS30 & MS45 \\
\hline Displacement (m) & 0.107 & 0.088 & 0.080 & 0.078 & 0.112 & 0.096 & 0.089 & 0.093 \\
Base shear (kN) & 3865 & 5403 & 5532 & 3417 & 3881 & 4923 & 5524 & 3260 \\
\hline
\end{tabular}




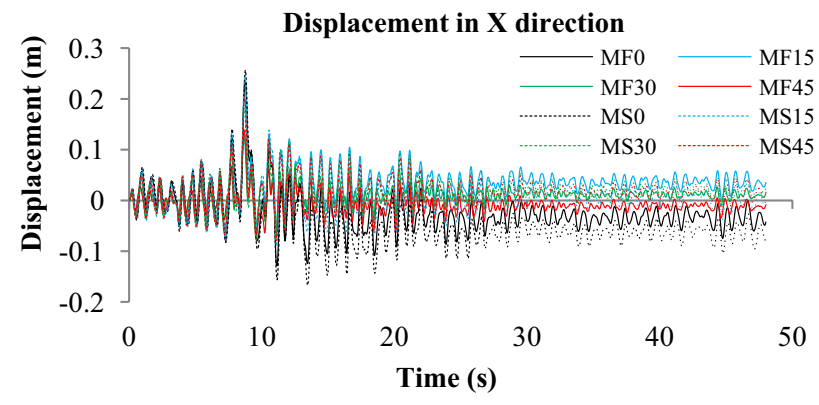

Fig. 14 Displacement in $X$ direction by nonlinear time history analysis

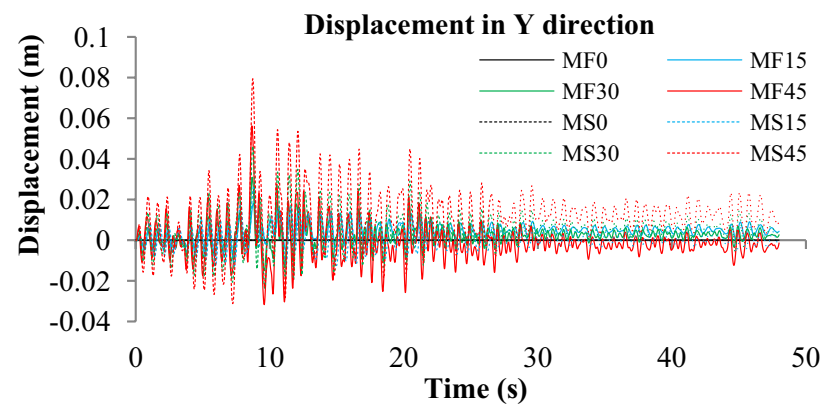

Fig. 15 Displacement in $Y$ direction by nonlinear time history analysis

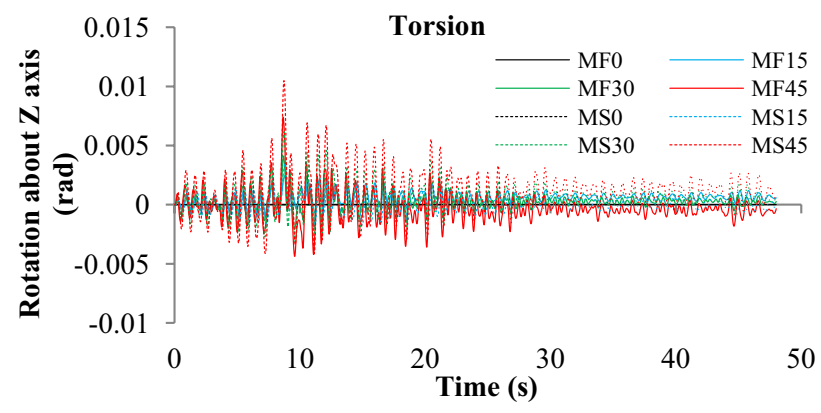

Fig. 16 Torsional response by nonlinear time history analysis

variation of mass, stiffness and geometry of the structures resting on slope, the twisting of the structure also takes place. Thus the columns on the higher side of the slope are subjected to heavy torsional force and these are also subjected to increased bending moment due to reduction of column height. The amount of bending moment on the columns of shorter side of the structure at higher level of slopes increases with the increment of level as well as slope angle, even if there is no reduction of column length. The importance of SSI is also revealed here, as the structures without SSI consideration overestimate the forces (base shear and bending moment) and underestimate the

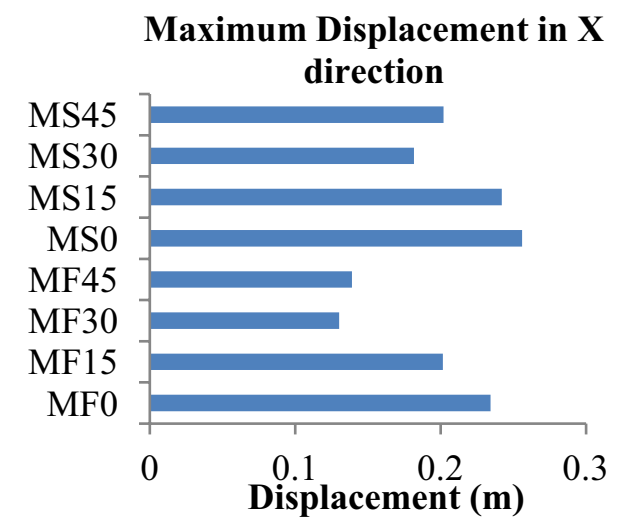

Fig. 17 Maximum displacement in $X$ direction from nonlinear time history

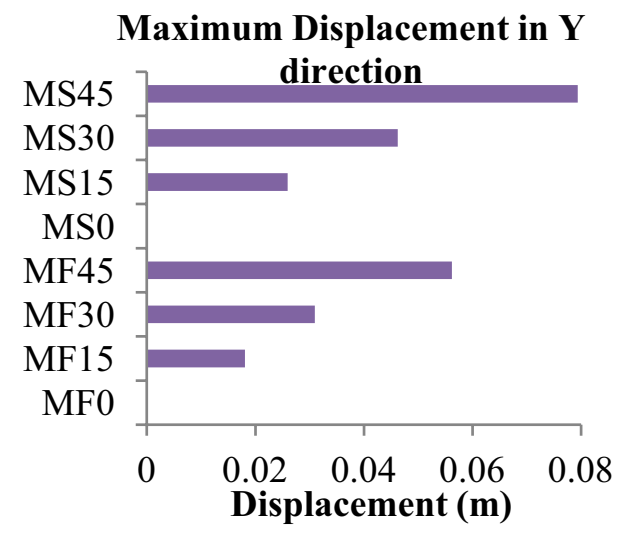

Fig. 18 Maximum displacement in $Y$ direction from nonlinear time history

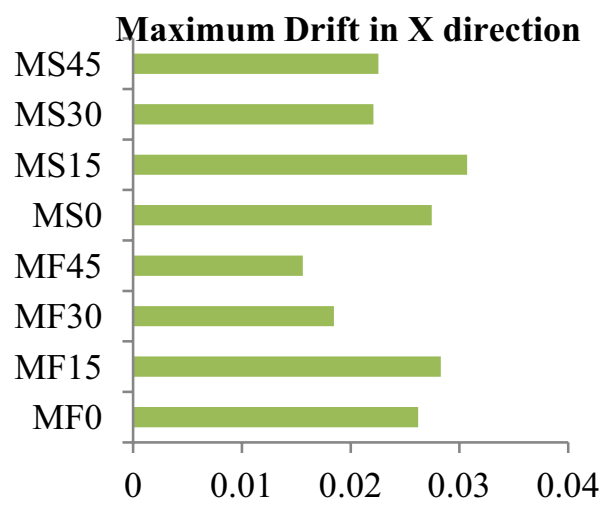

Fig. 19 Maximum drift in $X$ direction from nonlinear time history

responses (time period, displacement and torsion). This improper estimation of forces and responses can affect the structure very badly. So, this paper reflects the adverse effect of slope angle increment on the structures resting 


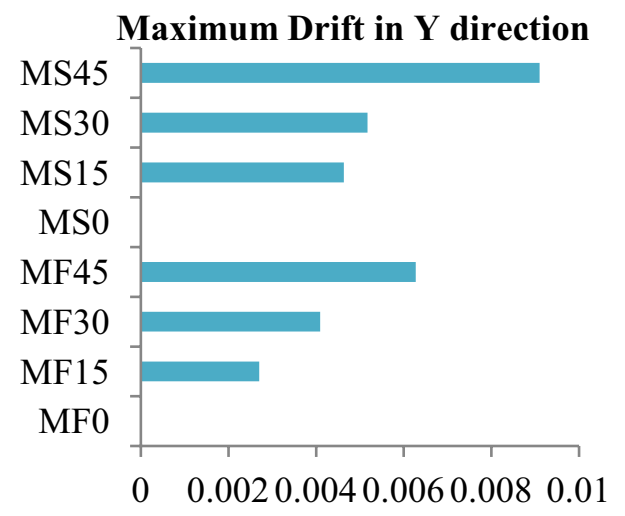

Fig. 20 Maximum drift in $Y$ direction from nonlinear time history

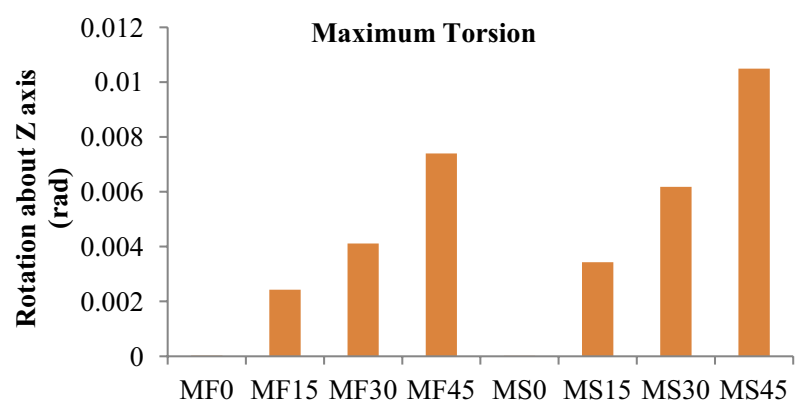

Fig. 21 Maximum torsional response from nonlinear time history

on sloping ground and recommends taking special care during the design of columns on the higher level of the slope of structures. This paper also emphases for considering SSI during the analysis of structures under earthquake load. There are few limitations of the work such as plan irregularity is not considered here, and only one-way slope is considered. These limitations are included in the future scope of the work.

Open Access This article is distributed under the terms of the Creative Commons Attribution 4.0 International License (http://creativeco mmons.org/licenses/by/4.0/), which permits unrestricted use, distribution, and reproduction in any medium, provided you give appropriate credit to the original author(s) and the source, provide a link to the Creative Commons license, and indicate if changes were made.

\section{References}

American Society of Civil Engineers, ASCE/SEI 41-13 (2014) Seismic evaluation and retrofit of existing buildings. Reston, Virginia

Applied Technology Council, ATC-40 (1996) Seismic evaluation and retrofit of concrete buildings. Applied Technology Council, California

Arjun S, Arathi S (2016) A study on dynamic characteristics of RC buildings on hill slopes. Int J Sci Res 5(7):1116-1119

Birajdar BG, Nalawade SS (2004) Seismic analysis of buildings resting on sloping ground. In: 13th world conference on earthquake engineering, Vancouver, B.C, Canada, 1(6)

Chougule AR, Dyavanal SS (2015) Seismic soil-structure interaction of buildings with rigid and flexible foundation. Int J Sci Res 4(6):513-517

Federal Emergency Management Agency, FEMA-356 (2000) Prestandard and commentary for seismic rehabilitation of buildings. Federal Emergency Management Agency, Washington DC

Gazetas G (1991) Formulas and charts for impedances of surface and embedded foundations. J Geotech Eng 117(9):1363-1381

Ghosh R, Debbarma R (2017) Performance evaluation of setback buildings with open ground storey on plain and sloping ground under earthquake loadings and mitigation of failure. Int J Adv Struct Eng 9(2):97-110

Halkude SA, Kalyanshetti MG, Ingle VD (2013) Seismic analysis of buildings resting on sloping ground with varying number of bays and hill slopes. Int J Eng Res Technol 2(12):2278-2281

IS 1893 (2002) Criteria for earthquake resistant design of structure, part 1. Bureau of Indian Standards, New Delhi

Kalsulkar N, Rathod S (2015) Seismic analysis of RCC building resting on sloping ground with varying number of bays and hill slopes. Int J Curr Eng Technol 5(3):2063-2069

Khadiranaikar RB, Masali A (2014) Seismic performance of buildings resting on sloping ground - a review. IOSR J Mech Civil Eng 11(3):12-19

Kumar S, Garg V, Sharma A (2014) Effect of sloping ground on structural performance of Rcc building under seismic load. Int J Sci Eng Technol 2(6):1310-1321

Nagarjuna, Patil SB (2015) Lateral stability of multi storey building on sloping ground. Int Res J Eng Technol 2(4):1162-1169

Prashant D, Kori JG (2013) Seismic response of one way slope RC frame building with soft storey. Int J Emerg Trends Eng Dev 5(3):311-320

Thombre P, Makarande SG (2016) Seismic analysis of building resting on sloping ground. J Emerg Technol Innov Res 3(6):296-300

Publisher's Note Springer Nature remains neutral with regard to jurisdictional claims in published maps and institutional affiliations. 